\title{
Energy-dispersive diffraction studies of inert anodes
}

\author{
Nicola V. Y. Scarlett, Ian C. Madsen, John S. O. Evans, Alan A. Coelho, \\ Katherine McGregor, Matthew Rowles, Marshall R. Lanyon and Andrew J. \\ Urban
}

J. Appl. Cryst. (2009). 42, 502-512

\section{IUCr Journals CRYSTALLOGRAPHY JOURNALS ONLINE}

Copyright (C) International Union of Crystallography

Author(s) of this paper may load this reprint on their own web site or institutional repository provided that this cover page is retained. Republication of this article or its storage in electronic databases other than as specified above is not permitted without prior permission in writing from the IUCr.

For further information see http://journals.iucr.org/services/authorrights.html 
Journal of

Applied

Crystallography

ISSN 0021-8898

Received 26 June 2008

Accepted 9 March 2009

(C) 2009 International Union of Crystallography Printed in Singapore - all rights reserved

\section{Energy-dispersive diffraction studies of inert anodes}

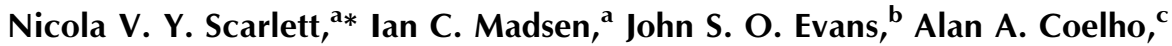 \\ Katherine McGregor, ${ }^{a}$ Matthew Rowles, ${ }^{a}$ Marshall R. Lanyon ${ }^{a}$ and Andrew J. \\ Urban $^{\mathrm{a}}$
}

\begin{abstract}
${ }^{a}$ CSIRO Minerals, Box 312, Clayton South, Victoria 3169, Australia, bepartment of Chemistry, Durham University, Science Laboratories, South Road, Durham, UK, and ${ }^{\mathrm{c} C o e l h o ~ S o f t w a r e, ~}$ Brisbane, Australia. Correspondence e-mail: nicola.scarlett@csiro.au
\end{abstract}

\begin{abstract}
A tomographic study of electrochemical cells to observe scales formed on inert anodes has been conducted using energy-dispersive synchrotron X-ray diffraction. This study is preparatory to an investigation that will observe this formation in situ during the cells' operation. The purpose of the current work was to determine whether this technique would be appropriate for such a study in terms of its sensitivity and whether the results could be quantified satisfactorily. A method has been developed for the quantitative phase analysis of energy-dispersive data using crystal-structure-based Rietveld refinement. This has been tested with standard materials and found to be comparable in accuracy to results obtained from traditional angular-dispersive diffraction. The lower limits of detection of the method have not been established quantitatively but qualitative differences can be seen between cells that have been cycled at different times. These differences indicate a linear relationship between scale formation and electrolysis time.
\end{abstract}

\section{Introduction}

The aim of this work was to develop a method whereby the internal features of an operating electrochemical cell could be phase mapped quantitatively without destroying the cell. Traditionally, for electrochemical investigations in molten salts, most characterization of starting materials and products relies upon ex situ techniques, both prior to and following electrolysis. Information obtained in this manner is often subject to experimental artefacts brought about by changes that may take place during preparation of samples for analysis. This is particularly true for many microscopic techniques in which the procedures frequently involve substantial physical changes (e.g. drying, embedding in epoxy, cutting, polishing, carbon coating etc.). In order to interpret changes in cell current and voltage and relate these unequivocally to electrode processes, in situ observations of electrodes and cell materials in their functional states, i.e. during electrolysis, are desirable. In situ spectroscopic techniques are commonly used to study electrochemical processes in aqueous solution. However, such methods are particularly challenging for molten-salt processes conducted at high temperatures, although Frazer and co-workers (McGregor et al., 2007) have developed a 'see-through' cell for visual inspection of the cell contents during electrolysis.

The cells chosen for this study are for the production of titanium metal using inert titanium oxide anodes rather than traditional carbon anodes. These have the advantage of evolving only oxygen at the anode during the course of reaction rather than carbon dioxide as is produced in conventional electrochemical cells. The electrode reactions for the process are as follows, with the cathode reaction given by equation (1), the anode by equation (2) and overall by equation (3):

$$
\begin{gathered}
\mathrm{TiO}_{2}+4 e^{-} \rightarrow \mathrm{Ti}+2 \mathrm{O}^{2-}, \\
2 \mathrm{O}^{2-} \rightarrow \mathrm{O}_{2}+4 e^{-}, \\
\mathrm{TiO}_{2} \rightarrow \mathrm{Ti}+\mathrm{O}_{2} .
\end{gathered}
$$

To date, all characterization of materials has relied upon $e x$ situ techniques [powder X-ray diffraction, scanning electron microscopy, electron-probe microanalysis (EPMA)].

For this investigation, we have used a Magnéli-phase material (Ebonex, general formula $\operatorname{Ti}_{n} \mathrm{O}_{2 n-1}$, where $n$ is in the range 4-10) as a model 'inert' anode. The Magnéli-phase material has been chosen as a model system for initial analysis because the phase changes that occur in the material during electrolysis have been substantially characterized ex situ (McGregor et al., 2006). The material is a metallic conductor, and is composed of a mixture of $\mathrm{Ti}_{4} \mathrm{O}_{7}, \mathrm{Ti}_{5} \mathrm{O}_{9}$ and $\mathrm{Ti}_{6} \mathrm{O}_{11}$. The Magnéli-phase material is immersed in the molten electrolyte, or bath, which in this experiment comprises calcium chloride $\left(\mathrm{CaCl}_{2}\right)$ with a small amount of calcium oxide $(\mathrm{CaO})$ impurity (temperature $\sim 1273 \mathrm{~K}$ ). Upon immersion, there is dynamic formation of a very thin low-calcium titanate layer at the electrode surface, with an even thinner $\mathrm{CaTiO}_{3}$ layer on top of that (total $10-40 \mu \mathrm{m}$ thick); this protects the anode initially 
and has been observed in post mortem EPMA studies. It is believed that this forms via reaction of $\mathrm{CaO}$ (from the bath) with traces of $\mathrm{TiO}_{2}$ formed on the electrode surface during heat-up as given in equation (4):

$$
\mathrm{CaO}+\mathrm{TiO}_{2} \rightarrow \mathrm{CaTiO}_{3} .
$$

There is some evidence that the $\mathrm{CaTiO}_{3}$ layer is gradually worn away during the electrolysis process, but the mechanism and wear rate are not known. After $\sim 8 \mathrm{~h}$ of electrolysis, the Magnéli-phase material is eventually oxidized to nonconducting $\mathrm{TiO}_{2}$ by oxygen gas (the anode product).

To probe these changes, high-energy white-beam synchrotron radiation has been used, which allows examination of the internal features of relatively large samples (Hall et al., 1998, 2000; Barnes et al., 2000). This enables these features to be mapped with respect to their position within an object. Diffraction data in such an environment may be measured by energy-dispersive detectors to produce a spectrum of diffracted intensity versus energy. This paper demonstrates a method for analysis of such energy-dispersive diffraction (EDD) data via the whole-pattern Rietveld method (Rietveld, 1969; Young, 1993). Traditionally, analysis of EDD data has required the conversion of data collected on the energy scale to a $d$-spacing scale (Larson \& Von Dreele, 1985; Ballirano \& Caminiti, 2001) and considers only the refinement of peak position and cell parameters via methods such as those of LeBail et al. (1988). The method used in this study differs in that it operates directly in energy space and uses crystal structures to calculate a pattern, which allows quantification using established methods (Hill \& Howard, 1987). This requires the careful description of the incident beam intensity characteristics and consideration of the absorption effects of the sample on the observed data. The method has been developed using a number of standard materials including 'sample 1' from the International Union of Crystallography (IUCr) Commission on Powder Diffraction (CPD) round robin on quantitative phase analysis (Madsen et al., 2001).

It should be noted that there has been some previous work describing the application of laboratory-based energy-dispersive diffraction to an electrochemical system (Panero et al., 2000, 2001; Ronci et al., 2000, 2001; Rossi Albertini et al., 2001). The electrochemical experiments described in these papers involved the cycling at room temperature of tiny amounts of lithium battery material in a purposely designed cell, which is appropriate only to the diffraction experiment. The small sample size is necessary in their case as they are using a laboratory X-ray source (maximum energy of $\sim 55 \mathrm{keV}$ ) rather than high-energy synchrotron $\mathrm{X}$-rays (maximum energy of $\sim 105 \mathrm{keV}$ ). The experiment described in the current work concerns the precursor to observing the formation of scale phases on inert anodes during the electrowinning of titanium at $1223 \mathrm{~K}$ in molten calcium chloride. The diffraction work is carried out on a realistic electrochemical cell, i.e. not one designed purely to allow the diffraction analysis. This ensures that the electrochemical findings are not influenced by constraints introduced by the analytical technique. The earlier work also deals only with lattice parameter variations in single-phase material determined via peak fitting. The current work deals with the formation of scale phases in a multi-phase system and their quantification via the Rietveld method.

This paper describes preliminary method development where static (non-operating) cells were examined using EDD to determine whether or not the resultant data could be quantified at sufficiently low levels of detection as to warrant designing a high-temperature, in situ electrochemical experiment to exploit this methodology. The samples were obtained by performing a series of electrolyses at high temperature $(1223 \mathrm{~K})$, and then 'freezing' the bath at selected stages of the reaction. The intact alumina crucibles, containing the anode and cathode materials and frozen bath $\left(\mathrm{CaCl}_{2}\right)$, were taken to Station 16.4, Synchrotron Radiation Source (SRS), at Daresbury Laboratories for EDD analysis.

\section{Experimental}

\subsection{Diffraction equipment}

Station 16.4 at Daresbury SRS receives high-energy white radiation from a $6 \mathrm{~T}$ wiggler to produce diffraction peaks from crystalline samples. The usable energy range is between 20 and $100 \mathrm{keV}$ with maximum intensity in the $40-60 \mathrm{keV}$ range. The use of high-energy white radiation allows relatively simple incident beam optics and a simple exit path to the detector compared with monochromatic instruments. It also provides very high penetration and thus makes the beamline suitable for examining large samples. Fig. 1 shows a schematic layout of the tomographic energy-dispersive diffraction imaging (TEDDI) equipment.

Diffracted beams are measured using an energy-discriminating, three-element, liquid nitrogen cooled, Ge solid-state detector system. The use of three detector elements at different diffraction angles ( $2 \theta$ values) permits observation of a wider range of $d$ spacing, as shown in Fig. 2. This gives simultaneous collection of all data which allows rapid collection times, thus making the beamline suitable for dynamic studies. The use of three detector elements also facilitates the discrimination of fluorescence from diffraction since fluorescence peaks occur at the same energy in all detectors whereas

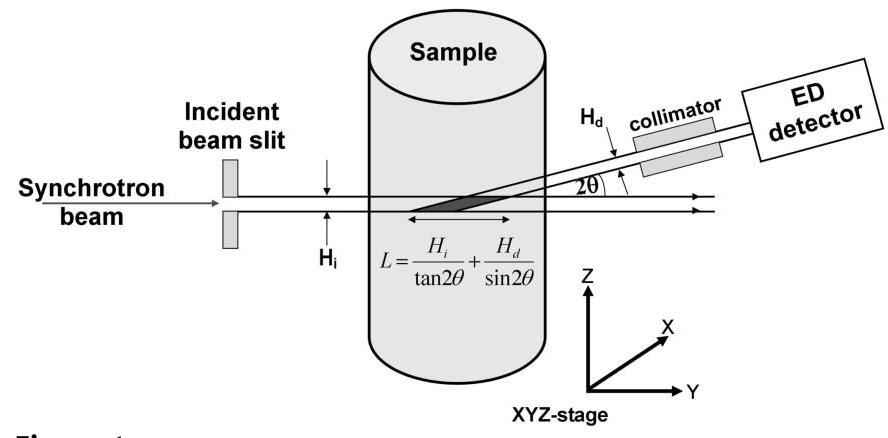

Figure 1

The experimental arrangement for TEDDI. The length of the active area (lozenge), $L$, is given by the function relating the incident and diffracted beam heights $\left(H_{\mathrm{i}}\right.$ and $H_{\mathrm{d}}$, respectively) and the angle of diffraction $(2 \theta)$. 
diffraction peaks of the same $d$ spacing are observed at different energies in each detector. This is demonstrated by the rutile (110) reflection marked at different energies on the data from the top and middle detectors shown in Fig. 2.

The volume of the sample being examined is referred to as the 'active' volume and is defined by the intersection of the paths of the incident beam and the detector collimator. This intersection creates a lozenge-shaped area of investigation (see Fig. 1) referred to as the diffraction lozenge. This active area is fixed in space and the sample may be scanned through it in order to map its internal features. Its length is a function of the incident $\left(H_{\mathrm{i}}\right)$ and diffracted $\left(H_{\mathrm{d}}\right)$ beam heights and the angle of diffraction $(2 \theta)$ as given in equation (5),

$$
L=\frac{H_{\mathrm{i}}}{\tan 2 \theta}+\frac{H_{\mathrm{d}}}{\sin 2 \theta},
$$

and is constant throughout our measurements. It should be noted that $L$ will have different values for each detector.

\subsection{Sample preparation and environment}

2.2.1. Standards. EDD data sets were collected on a series of standard materials in order to (i) characterize the instrument where possible and (ii) determine the accuracy of the quantitative phase analysis method developed. The standards used were taken from the IUCr CPD round robin on quantitative phase analysis conducted in 2000 (Madsen et al., 2001). The samples used here were yttria $\left(\mathrm{Y}_{2} \mathrm{O}_{3}\right)$ and the suite
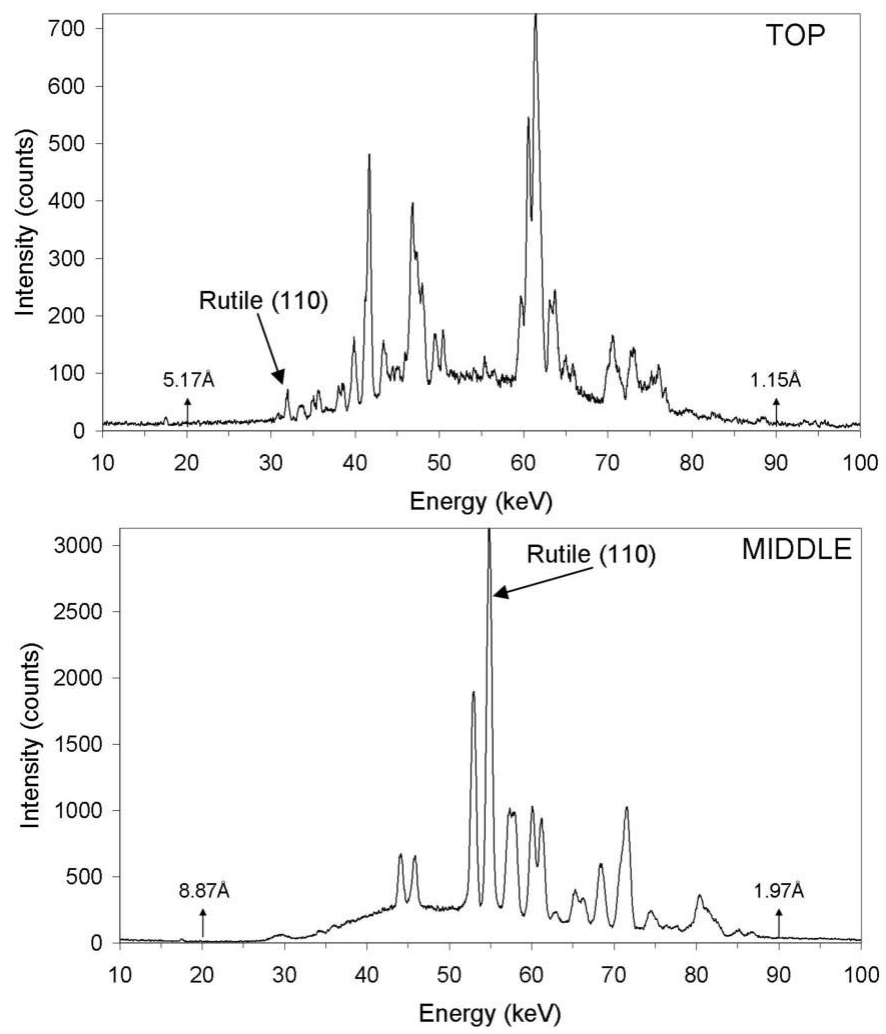

Figure 2

Data from the top and middle detectors in the TEDDI arrangement showing different $d$-spacing ranges covered by the same energy range. The (110) reflection of rutile is indicated in both data sets to highlight this difference. comprising round robin sample 1 , which consisted of a range of compositions of the three-phase mixture: corundum $\left(\mathrm{Al}_{2} \mathrm{O}_{3}\right)$, fluorite $\left(\mathrm{CaF}_{2}\right)$ and zincite $(\mathrm{ZnO})$. They were presented to the beam as loose powders in $1 \mathrm{~cm}$-diameter vials.

2.2.2. Electrochemical cells. Ebonex was obtained from Atraverda Ltd (UK) in plate form (100 mm diameter, 2-3 mm thick). The plates were cut with a diamond saw into bars that measured approximately $70 \times 7.5 \times 2-3 \mathrm{~mm}$. All bath chemicals were of high-purity grade $(>99 \%)$ obtained from Sigma-Aldrich. Prior to use, calcium chloride was dried at $393 \mathrm{~K}$ for $60 \mathrm{~min}\left(\mathrm{ramp}\right.$ rate $5 \mathrm{~K} \mathrm{~min}^{-1}$ ), then at $643 \mathrm{~K}$ for $12 \mathrm{~h}$ (ramp rate $0.11 \mathrm{~K} \mathrm{~min}^{-1}$ ), and stored in an oven at $453 \mathrm{~K}$. Additional drying under an argon atmosphere (overnight at $973 \mathrm{~K}$, then $1 \mathrm{~h}$ at $c a 1223 \mathrm{~K}$ ) was performed before electrolysis, during heating to the operating temperature ( $c$ a $1223 \mathrm{~K}$ ).

A laboratory-scale cell was used to perform the electrolysis tests. The electrolyses were conducted using bar-shaped anodes that were dipped into the melt to give an exposed area of about $5 \mathrm{~cm}^{2}$. The anode was assembled by placing the sample in a stainless steel holder that was connected to a stainless steel current collector. Alumina sleeves were used to protect the electrode holder and current collector from the oxidizing atmosphere. The tests were conducted under an argon cover gas (ultra high purity, 99.999\%) in a $\mathrm{CaCl}_{2}-\mathrm{CaO}$ $(0.2-5 \mathrm{wt} \%)$ electrolyte, at a temperature of approximately $1223 \mathrm{~K}$ and a current density of around $0.2 \mathrm{~A} \mathrm{~cm}^{-2}$ for times ranging from 0 to $8 \mathrm{~h}$. Alumina crucibles were employed, and a pasted/dried $\mathrm{TiO}_{2}$ cathode was used. Fig. 3 shows the cell configuration (left), and an actual cell (right), with a view of the anode and cathode positions.

Electrolyses were conducted by applying a constant current supplied by a PAR Model 362 Scanning Potentiostat fitted with a PAR Model 365 current booster (maximum 10 A). Cell voltage, current and bath temperature were measured and recorded every second. A series of electrolyses were

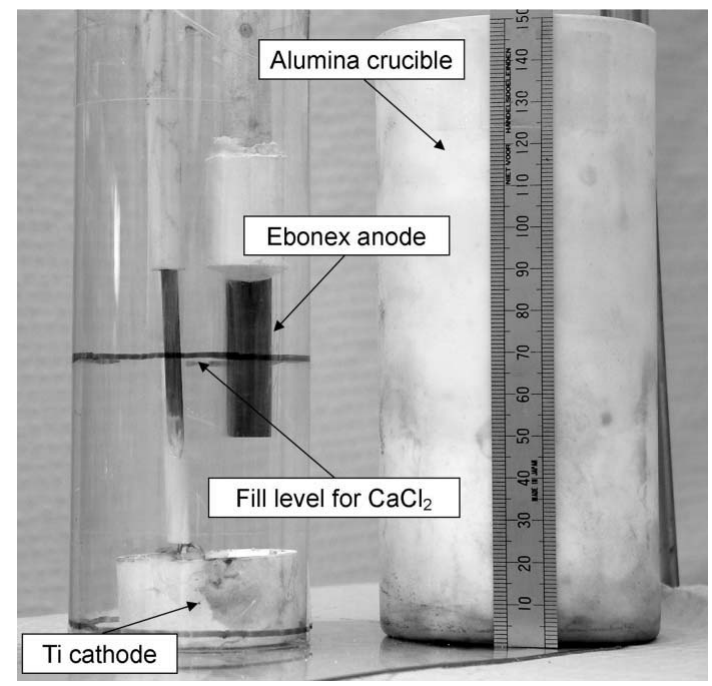

Figure 3

A model of the electrolytic cell (left) showing positions of the anode and cathode and the fill level of the electrolyte. An actual cell is shown on the right. 
Table 1

Phase contents of the Ebonex starting material derived from Rietveld refinement using TOPAS (Bruker, 2003).

\begin{tabular}{lllll}
\hline & Rutile & $\mathrm{Ti}_{4} \mathrm{O}_{7}$ & $\mathrm{Ti}_{5} \mathrm{O}_{9}$ & $\mathrm{Ti}_{6} \mathrm{O}_{11}$ \\
\hline QPA & 0.8 & 2.3 & 57.3 & 39.6 \\
\hline
\end{tabular}

performed for varying amounts of time, then the cells were allowed to cool. On cooling, they were sealed with epoxy resin to minimize hydration of the $\mathrm{CaCl}_{2}$ and to preserve the system as accurately as possible.

\subsection{Characterization of starting materials}

The samples from the IUCr CPD round robin ('sample 1') had been fully characterized in the preparation for that work and are described by Madsen et al. (2001). A sample of the Ebonex was ground to a fine powder using a McCrone microniser, and Bragg-Brentano diffraction data $(\mathrm{Cu} K \alpha)$ were collected in the laboratory. Fig. 4 shows the results of Rietveld refinement for this sample. The literature models for $\mathrm{Ti}_{5} \mathrm{O}_{9}$ and $\mathrm{Ti}_{6} \mathrm{O}_{11}$ (Andersson \& Jahnberg, 1960) were only approximate for the materials found in this sample. Refinement of their structures improved the fit somewhat but they are still only approximations. However, these models should suffice for quantification based upon the $R_{\mathrm{wp}}$ of the refinement (6.64\%) along with the refined $R_{\mathrm{Bragg}}$ values for all phases of $3.69 \%$ (rutile), $4.05 \%\left(\mathrm{Ti}_{4} \mathrm{O}_{7}\right), 4.55 \% \quad\left(\mathrm{Ti}_{5} \mathrm{O}_{9}\right)$ and $4.96 \%$ $\left(\mathrm{Ti}_{6} \mathrm{O}_{11}\right)$. The results of quantification of this starting material are shown in Table 1.

\subsection{Synchrotron data collection}

Energy-dispersive diffraction data were collected for each electrolysis cell over an energy range of approximately 5$105 \mathrm{keV}$. Line scans along the $y$ direction were carried out at varying heights ( $z$ positions) along the anodes as shown in Fig. 5. Each scan comprised about 100-150 energy-dispersive diffraction data sets collected for between 60 and $200 \mathrm{~s}$ each. Fig. 6 shows schematically two positions of the anode with respect to the active volume described by the position of the

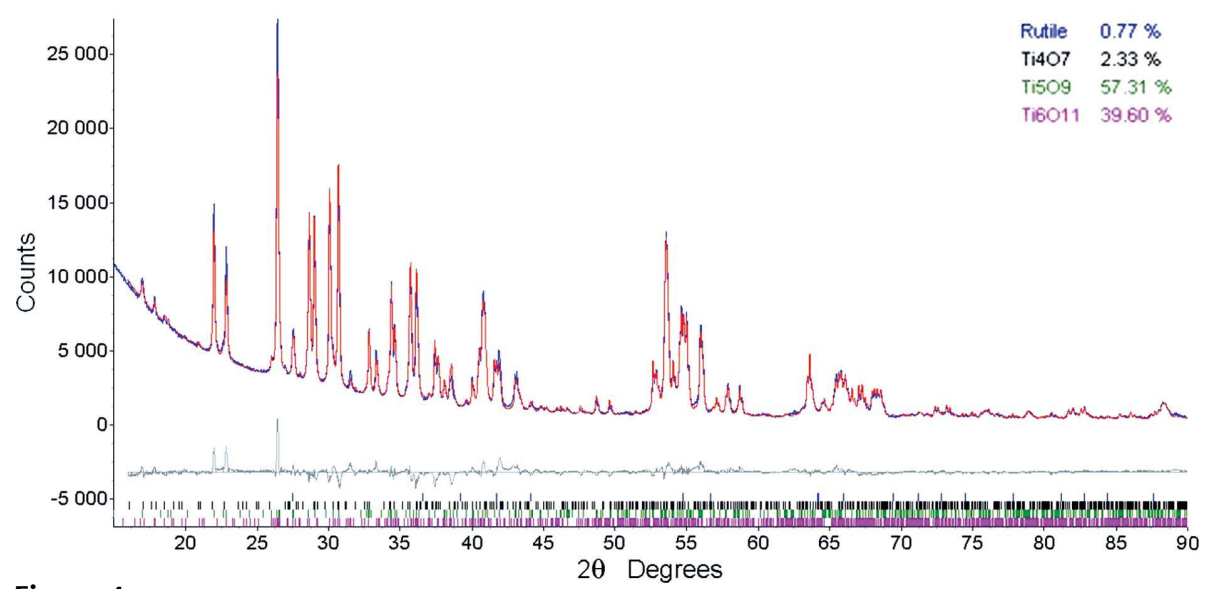

Figure 4

Results of Rietveld refinement of laboratory data collected from a ground sample of Ebonex. incident beam and the detector. The associated diffraction patterns obtained from these two regions are also shown.

The active volume for each data point was of the order of $1 \mathrm{~mm}$ in width by $10 \mathrm{~mm}$ in length. The scan rate was such that the spatial resolution of the data sets was $0.1 \mathrm{~mm}$. Depending upon the $z$ value of the scan, the beam passed through either the epoxy seal at the top of the anode or the $\mathrm{CaCl}_{2}$ bath material. This, accordingly, had a great effect upon the absorption of the beam, especially at lower energies, and as a consequence the patterns gained from within the $\mathrm{CaCl}_{2}$ were of considerably lower count rate and hence poorer counting statistics than those from above the bath level. It should be noted, however, that diffraction peaks from $\mathrm{CaCl}_{2}$ were not observed from any of the samples. Subsequent examination of the cells indicates that the epoxy seal at the top of the anode was not adequate to prevent hydration of the $\mathrm{CaCl}_{2}$ and that it was, in fact, liquid rather than crystalline. There was also great difficulty in actually locating the anodes within the opaque samples from the observed diffraction data alone.

\subsection{Data analysis}

2.5.1. Method development. The basis of diffraction is the satisfaction of Bragg's law,

$$
\lambda=2 d \sin \theta,
$$

where $\lambda$ is the monochromatic wavelength of the incident radiation, $d$ is the interplanar spacing of the diffracting phase and $2 \theta$ is the diffraction angle. In most laboratory or synchrotron powder diffractometers, $\lambda$ is fixed and $2 \theta$ is measured to determine $d$. This arrangement is referred to here as angle-dispersive diffraction (ADD).

Energy is related to wavelength via

$$
E_{\mathrm{keV}}=\frac{h c}{\lambda} 6.24 \times 10^{25}=\frac{12.4}{\lambda},
$$

where $E_{\mathrm{keV}}$ is the energy of the incident radiation in $\mathrm{keV}, h$ is Planck's constant $\left(6.626068 \times 10^{-34} \mathrm{~J} \mathrm{~s}^{-1}\right), c$ is the speed of light $\left(2.998 \times 10^{8} \mathrm{~m} \mathrm{~s}^{-1}\right)$ and $\lambda$ is the wavelength associated with that energy in ångströms. Substitution of a rearranged equation (7) into equation (6) enables the mapping of the measured energy scale into $d$ spacing,

$$
E_{\mathrm{keV}}=6.2 /(d \sin \theta),
$$

where $2 \theta$ is the angle between the incident beam and the detector slit (Fig. 1).

There are two fundamental differences between EDD and ADD which prevent the use of the majority of Rietveld programs for the analysis of EDD data. The first is that the EDD data are collected on an energy scale rather than a diffraction angle or $d$-spacing scale. This requires the calculated pattern to be put onto an energy scale as described above. Structure factors may then be extracted via whole 
powder pattern decomposition such as the method of Le Bail et al. (1988). This approach has been taken in several highpressure equation-of-state studies (Zhao et al., 1997, 2000; Frost \& Fei, 1999). However, it does not allow a direct measure of quantification via the ZMV algorithm of Hill \& Howard (1987) as occurs in whole powder pattern structure refinement using the method of Rietveld (1969). In the approach of Ballirano \& Caminiti (2001) laboratory-based energy-dispersive data are normalized according to the incident spectrum, corrected for absorption, then analysed in the GSAS crystallographic package (Larson \& Von Dreele, 1985) by converting to ADD format using a 'dummy' wavelength. This approach requires access to the incident spectrum, which was not possible at the synchrotron. The approach taken here is to adopt a structure-based Rietveld analysis approach using TOPAS (Bruker, 2003) to model the pattern directly on the energy scale by using algorithms that embody equation (8). This is achieved by defining a parameter for the wavelength which is dependent upon the fixed detector angle as given in equation (6) and using this in the calculation of energy in terms of $d$ spacing via equation (7). The energy returned is used to determine the structure factors used in the intensity calculations. The peak positions are then determined directly on an energy scale from unit-cell dimensions.

The second major difference between EDD and ADD is the nonlinear distribution of intensity in the incident beam as a function of energy. Accordingly, the relative intensities of the calculated peaks have to be modified to match the intensity profile of the incident spectrum. In addition, the distribution of intensities is further altered by absorption of the incident and diffracted X-rays in the sample and in the air and by the spectral response of the detector (Bordas et al., 1977). The effect of this absorption is to skew the intensity distribution to higher energies since the lower energies will be more heavily absorbed in the sample. The magnitude of this effect will increase as the absorption increases. This must be accounted for in the modelling of data of this type. Previous approaches (Bordas et al., 1977; Buras et al., 1979) have developed instrument functions to model these combined effects in a single asymmetric function such as a lognormal curve. Glazer et al. (1978) considered the expansion of a power function

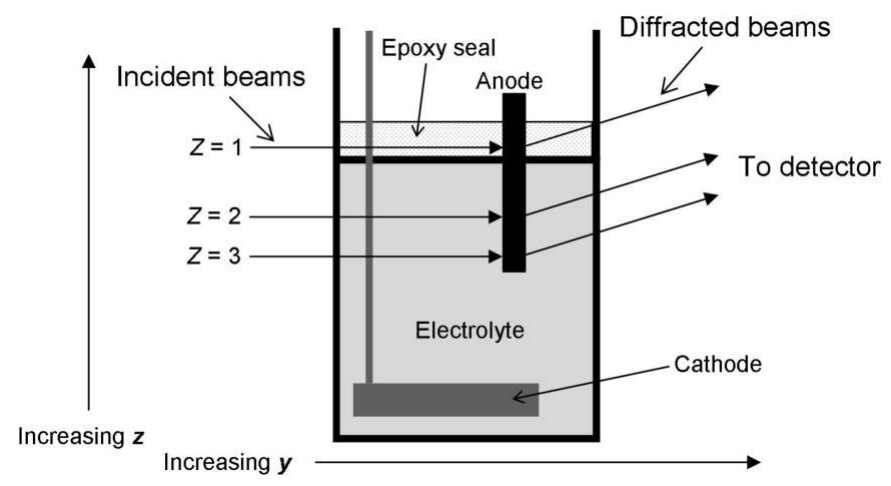

Figure 5

A diagram of the electrolytic cell showing the beam path at different $z$ values (heights). which requires the use of two separate functions to describe the intensity function before and after its peak; this approach is not particularly convenient for whole-pattern analysis.

Ideally, an independent assessment of the incident beam intensity distribution and the detector response would be made by measurement of the direct beam. However, on such high-energy beamlines this is generally not possible and so an empirical model has been determined for this work. It should be noted that filtration of the incident beam to prevent damage of the detectors by the direct beam was not considered as it would undoubtedly change the spectral distribution being measured. It may be possible, however, to obtain such a measurement during a synchrotron test day where the facility is operating at full energy but very low beam current.

In our method the intensity corrections are considered in two parts. The first part, related primarily to the intensity distribution in the incident beam and the detector efficiency, is
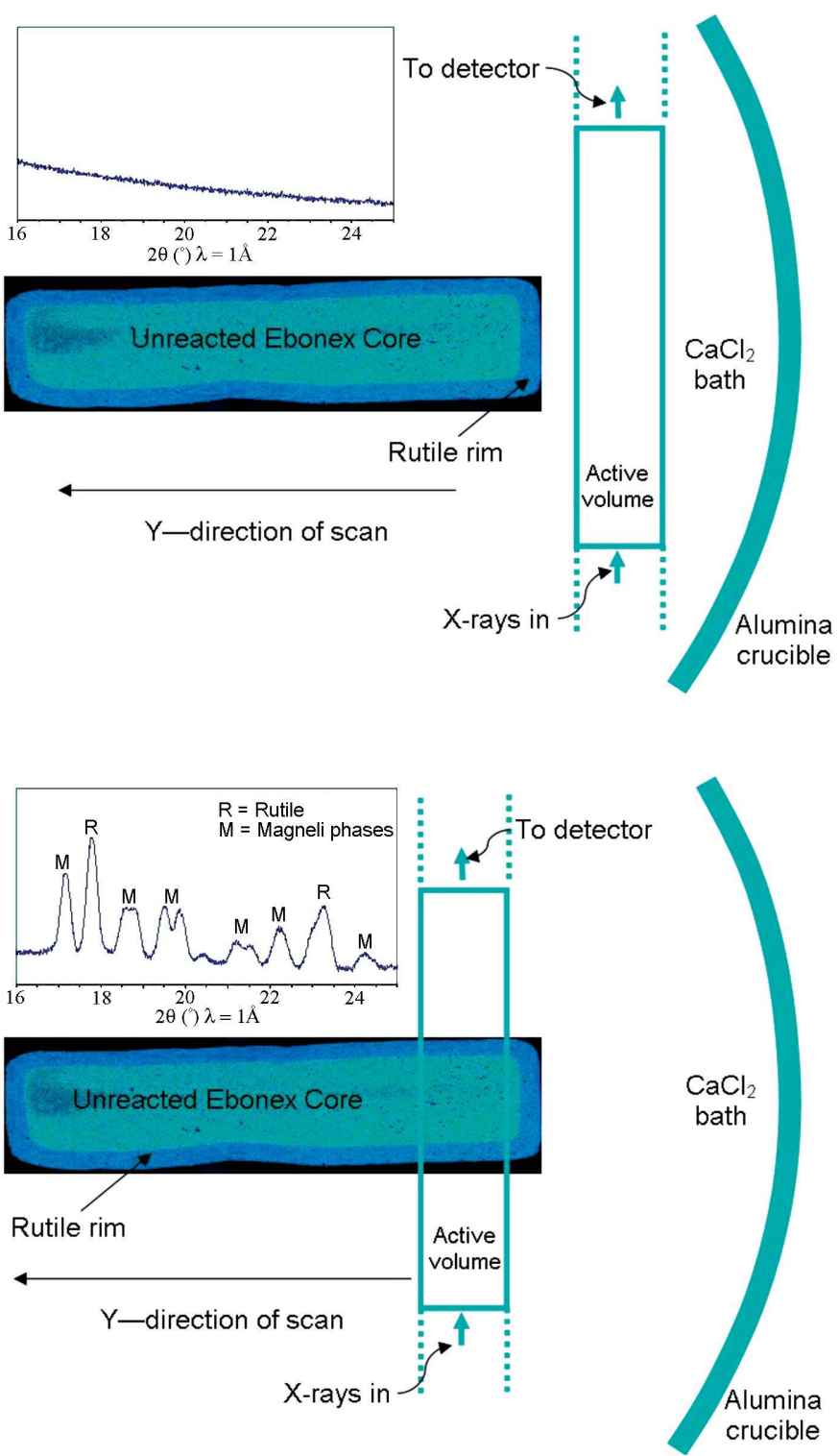

Figure 6

A diagram showing two positions of the anode with respect to the active volume of the diffractometer and their associated diffraction patterns. 
determined by measurement of standards. The second part is dependent upon the path of the beams through the sample and is refined along with other sample-related parameters. The first part was modelled using a Gaussian function [equation (9)] to calculate the intensity correction needed $\left(I_{\text {corr1 }}\right)$,

$$
I_{\text {corr } 1}=a \exp \left\{-0.5\left[\left(x-x_{0}\right) / b\right]^{2}\right\},
$$

where $x$ is the energy and $a, x_{0}$ and $b$ are refinable parameters relating to the height, position and FWHM of the peak, respectively.

The intensity variation attributable to absorption by the sample was modelled with an exponential function, $\mu t$, as given in equation (10). The form of this term was determined by modelling a plot of calculated values of mass absorption coefficient versus energy for the various compositions of sample 1. This function is intended to approximate the product of the mass absorption coefficient $(\mu)$ and the sample thickness $(t)$ in the relation given in equation (11), which describes the effect of absorption on the intensity of the diffracted beam. This term is also energy dependent:

$$
\mu t=c \exp \left(-d E_{\mathrm{keV}}\right)
$$

where $E_{\mathrm{keV}}$ is the energy and $c$ and $d$ are refinable parameters.

$$
I_{\text {corr } 2}=\exp (-\mu t) \text {. }
$$

The peaks were then scaled by the product of these functions given in equation (12):

$$
I_{\text {corr_total }}=I_{\text {corr1 }} I_{\text {corr2 }} \text {. }
$$

To determine the intensity characteristic of the detectors, the refinable parameters in equation (9) were determined using the standard suite comprising round robin sample 1 (Madsen et al., 2001). (Note that sample $1 g$ was excluded from this calibration refinement so it could be used later as a test of quantitative phase analysis using this method.) The parameters were refined using a 'surface analysis' approach where all data sets from both the top and the middle detectors were fitted simultaneously to the same structural models in the fashion described by Stinton \& Evans (2007). During this step, the intensity variation attributable to absorption [equation

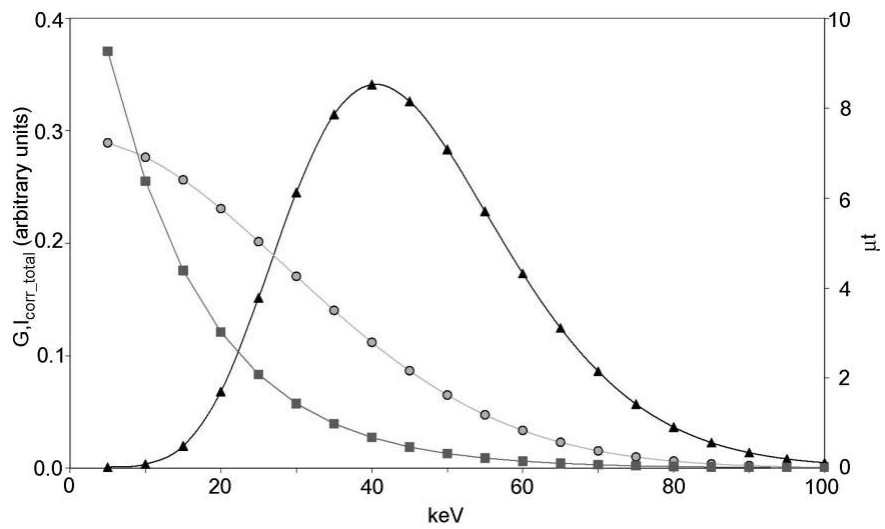

Figure 7

Functional forms of the intensity corrections for EDD showing $G$ as grey circles, $\mu t$ as grey squares and $I_{\text {corr_total }}$ as black triangles.
(11)] was constrained by the relative mass absorption coefficients of each of the samples in order to isolate the contribution of the instrument. Fig. 7 shows the functional forms of the intensity correction term and its components for sample $1 a$. Note that the final form of $I_{\text {corr_total }}$ may be approximated by a lognormal function. However, the approach taken here allows at least part of the function to be constrained by measurable instrumental parameters and the remainder to have some relationship to physical parameters of the sample. In fact, it is apparent that the quantitative phase analysis is not very sensitive to the precise functional form of $I_{\text {corr_total }}$. Such an empirical approach which relies on calibration using standard materials is therefore generally applicable.

It should also be pointed out that the samples considered here comprised mostly elements of low atomic number $(\mathrm{Ca}$, $\mathrm{Ti}, \mathrm{O}, \mathrm{Cl}$ ) and hence there was no absorption edge covered by the measured energy range. However, for samples that contain elements of high atomic number, their absorption edges would further alter the intensity distribution as a function of energy. The magnitude of the correction would be dependent upon the amount of the high atomic number elements present and could be incorporated as an additional term in equation (12). The form of this term may be taken from NIST's database (http://physics.nist.gov/PhysRefData/XrayMassCoef/ chap2.html) and would appear as shown in Fig. 8 for cerium $(K$ absorption edge $=40.44 \mathrm{keV}$ ) for example. It would also be necessary in such a case to include a group of peaks to account for the fluorescence peaks generated. These could be of fixed relative intensities according to the literature and scaled as a whole.

The peak shapes in the EDD data were dominated by the instrumental component. They were modelled using pseudoVoigt peak types with energy-dependent width and shape parameters. These models were detector specific and also had an energy-dependent sample-related component available to allow for small amounts of sample broadening contributing to the final width and shape.

\section{Figure 8}

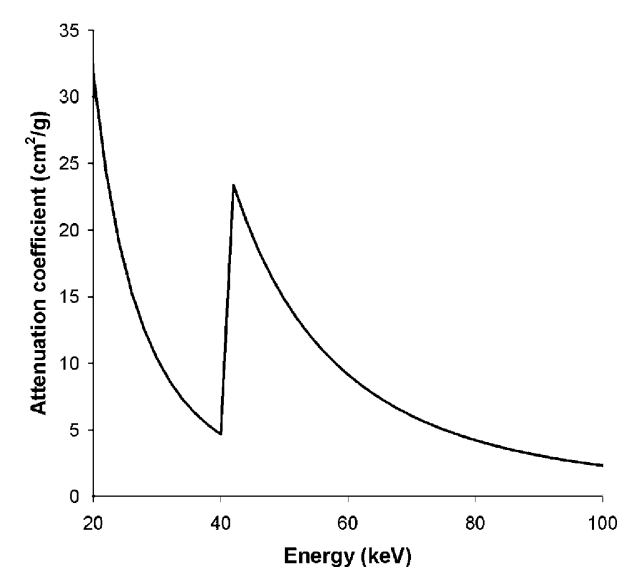

Attenuation coefficient of cerium shown for the energy range considered in this experiment $(K$ absorption edge $=40.44 \mathrm{keV})$. If such an element were present in these samples, this effect would need to be modelled in the intensity correction function $\left(I_{\text {corr_total }}\right)$. 
The width and shape parameters of the pseudo-Voigt functions were determined as shown in equations (13) and (14), where slope $_{\text {width }}$ and slope shape $_{\text {are refinable parameters }}$ and $d$ is the $d$ spacing:

$$
\begin{aligned}
\text { FWHM }_{\text {total }} & =\text { FWHM }+ \text { slope }_{\text {width }} d, \\
\text { Lorentz }_{\text {total }} & =\text { Lorentz }+ \text { slope }_{\text {shape }} d .
\end{aligned}
$$

These simple functions provided a satisfactory fit to the observed peak shapes (Fig. 9)

2.5.2. Crystallographic models. The crystallographic models used for the analysis of IUCr CPD sample 1 were corundum (Brown et al., 1993), fluorite (Weiss et al., 1957) and zincite (Xu \& Ching, 1993); and for the electrochemical cells $\mathrm{Ti}_{4} \mathrm{O}_{7}$ (Marezio \& Dernier, 1971), $\quad \mathrm{Ti}_{5} \mathrm{O}_{9}$ and $\mathrm{Ti}_{6} \mathrm{O}_{11}$ (Andersson \& Jahnberg, 1960), and rutile (Restori et al., 1987).

\section{Results and discussion}

\subsection{Standards}

Fig. 9 shows part of the results of the surface refinement of the sample 1 suite. For clarity, only sample $1 e$ (middle detector, blue; top detector, black) has been shown. Table 2 and Fig. 10 show the results of quantification of the sample 1 suite using this method. The method was then tested on sample $1 g$ with the Gaussian parameters $a, b$ and $x_{0}$ fixed to the values determined from the other mixtures in the sample 1 suite. The results are shown in red in Fig. 10. The results shown in Table 2 and Fig. 10 show very good agreement between the weighed and measured values for each of the samples considered. This

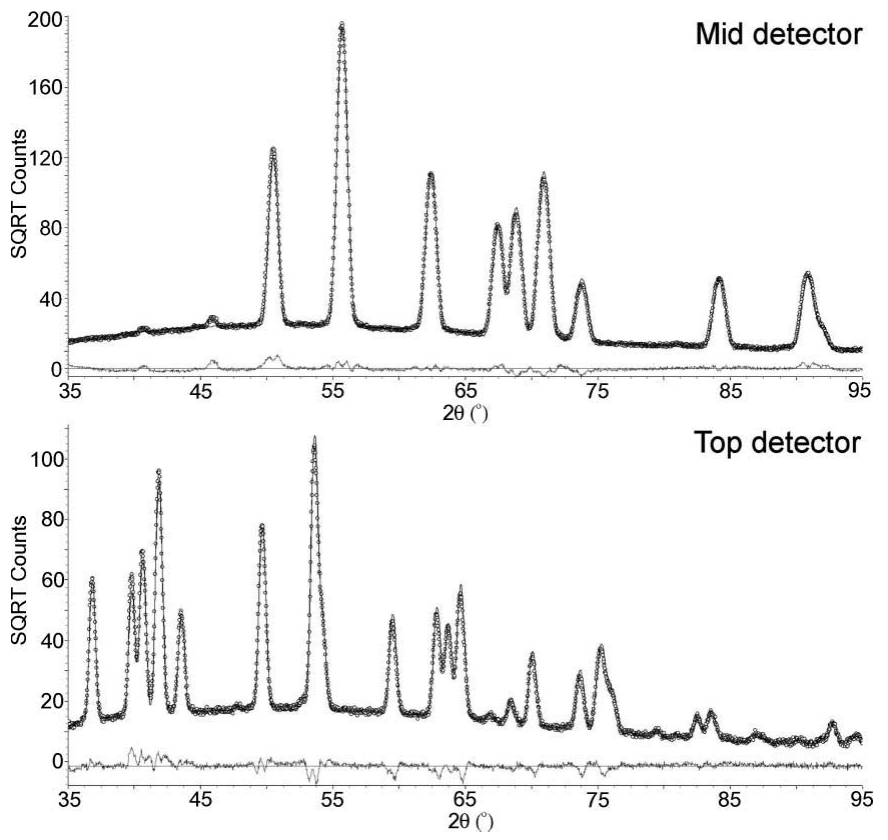

Figure 9

Results of Rietveld refinement of sample $1 e$ taken from the surface refinement of the sample 1 suite. Data points are shown as open circles and the calculated pattern as solid lines. Difference curves are shown in grey at the bottom of the plot.
Table 2

Weighed and measured (EDD) quantitative phase analysis of IUCr CPD sample 1 .

\begin{tabular}{lrrrrrrrr}
\hline & \multicolumn{2}{l}{ Corundum $(\mathrm{wt} \%)$} & & \multicolumn{2}{l}{ Fluorite $(\mathrm{wt} \%)$} & & \multicolumn{2}{l}{ Zincite $(\mathrm{wt} \%)$} \\
\cline { 2 - 3 } Sample & Weighed & EDD & & Weighed & EDD & & Weighed & EDD \\
\hline $1 a$ & 1.15 & 1.56 & & 94.81 & 94.65 & & 4.04 & 3.79 \\
$1 b$ & 94.31 & 94.60 & & 4.33 & 4.16 & & 1.36 & 1.24 \\
$1 c$ & 5.04 & 6.21 & & 1.36 & 1.41 & & 93.59 & 92.38 \\
$1 d$ & 13.53 & 14.03 & & 53.58 & 55.17 & & 32.89 & 30.80 \\
$1 e$ & 55.12 & 55.91 & & 29.62 & 29.87 & & 15.25 & 14.23 \\
$1 f$ & 27.06 & 28.32 & & 17.72 & 18.26 & & 55.22 & 53.42 \\
$1 g \dagger$ & 31.37 & 32.82 & & 34.42 & 35.06 & & 34.21 & 33.13 \\
\hline
\end{tabular}

$\dagger$ Sample $1 \mathrm{~g}$ measured separately from the calibration refinement used on the other members of the sample 1 suite.

means that quantitative phase analysis can be achieved directly from TEDDI data and that the move to an in situ experiment is possible.

\subsection{Electrochemical cells}

For each line scan of the electrochemical cells, the data from the top and middle detectors were plotted as shown in Fig. 11 and assessed qualitatively. These figures were used in the phase identification process. The only phases observed in all samples were two of the Magnéli phases, $\mathrm{Ti}_{5} \mathrm{O}_{9}$ and $\mathrm{Ti}_{6} \mathrm{O}_{11}$, and rutile. No evidence of $\mathrm{CaTiO}_{3}$ formation was seen, which is consistent with ex situ X-ray diffraction (XRD) studies carried out on similar anodes (McGregor et al., 2006). This is to be expected, as such a thin layer as was observed in EPMA studies may only represent a weight fraction of less than $0.5 \mathrm{wt} \%$; this is probably below the detection limits of XRD in this environment, especially considering the relatively large active volume considered here. Fig. 11 shows accumulated EDD patterns from a cell cycled for $10 \mathrm{~min}$. This particular line scan has been taken above the level of the electrolyte through the epoxy seal. The diffraction lines from each phase can be clearly seen and the position difference between the start of the rutile peaks and the Magnéli phases $\left(\mathrm{Ti}_{5} \mathrm{O}_{9}\right.$, $\left.\mathrm{Ti}_{6} \mathrm{O}_{11}\right)$ is apparent. Fig. 12 shows results from the same cell as

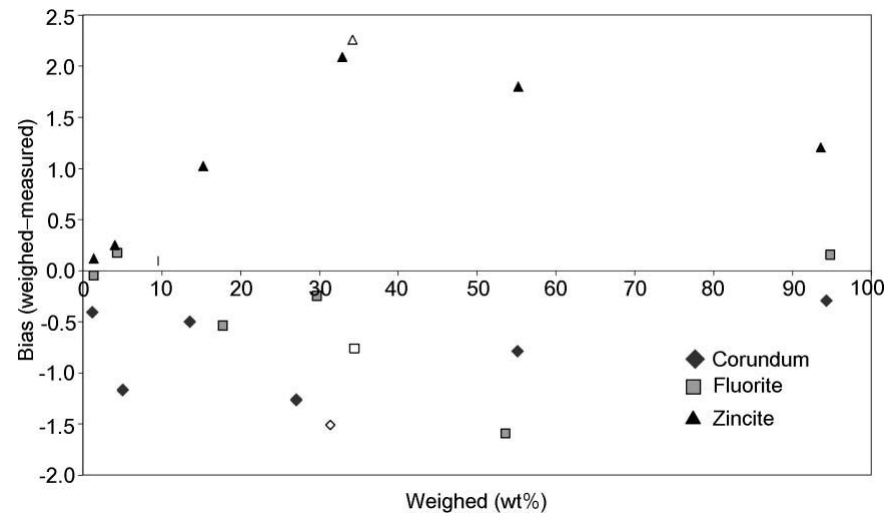

Figure 10

Results of quantification of the EDD data collected from the sample 1 suite and analysed using the intensity and peak shape corrections described in \$2.5.1. The open symbols show the results of the method when tested on sample $1 g$. 
Fig. 11 but this time with the beam path travelling through the electrolyte at about $10 \mathrm{~mm}$ below the $\mathrm{CaCl}_{2}$ surface. The quality of the data is clearly diminished as absorption by the $\mathrm{CaCl}_{2}$ has effectively removed the lower-energy lines from the diffraction data. However, the difference between the starting positions of the rutile peaks and the Magnéli phases is still apparent.

Fig. 13 shows similar plots to Fig. 11 only viewed down the energy axis rather than the intensity axis for cells subjected to electrolysis for 0,10 and $240 \mathrm{~min}$. This shows directly the differences in distance along the anode between a rutile peak (011) and a peak from one of the Magnéli phases $\left(\mathrm{Ti}_{5} \mathrm{O}_{9}, 111\right)$. These differences give an approximation of the thickness of the rutile layer on the anode surface as a function of electrolysis time.

Fig. 14 shows the results of quantitative phase analysis (QPA) of the diffraction data collected from a cell cycled for 10 min (a) above the level of the $\mathrm{CaCl}_{2}$ (i.e. Fig. 11) and (b) below the level of the $\mathrm{CaCl}_{2}$ (i.e. Fig. 12). The balance of the
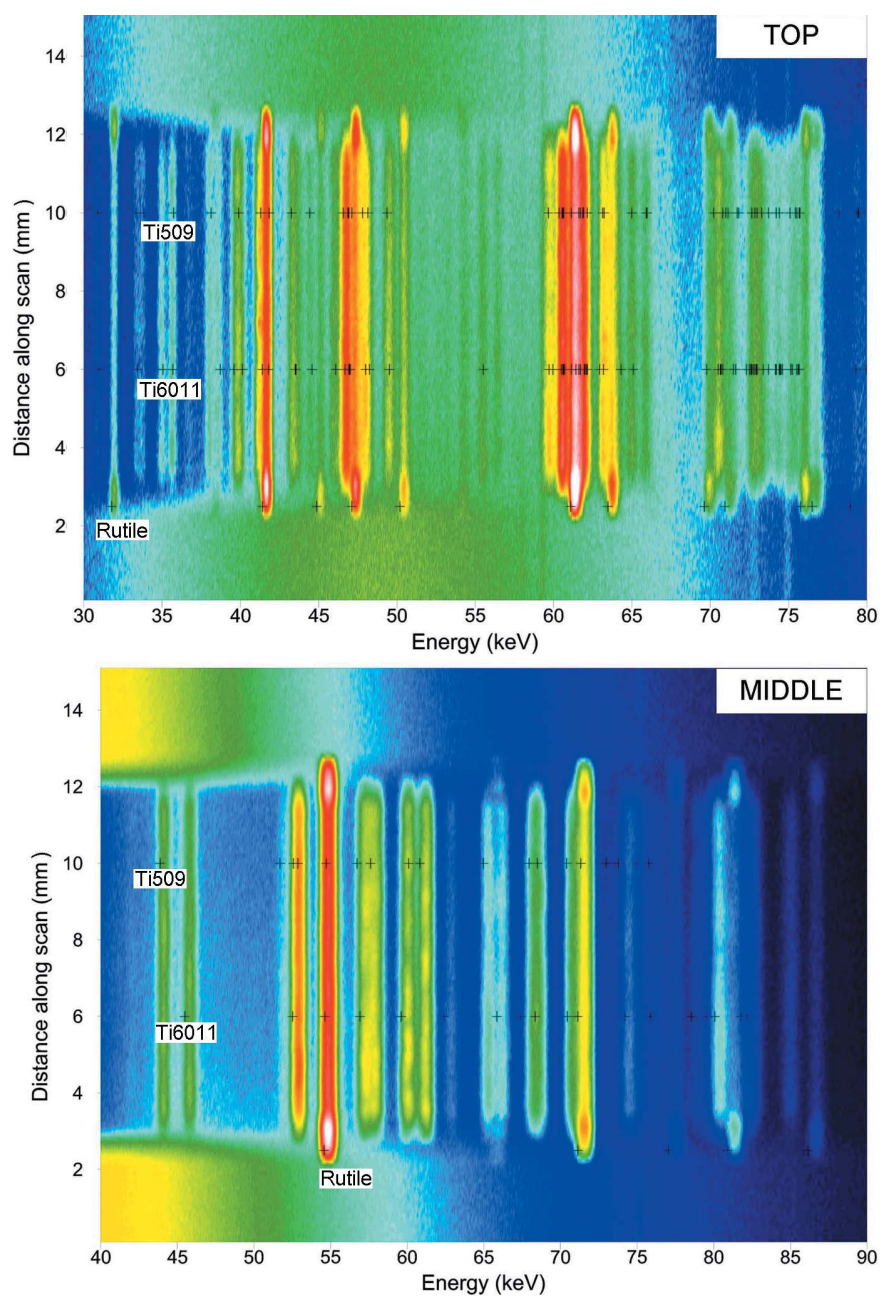

Figure 11

Accumulated EDD patterns from a cell cycled for $10 \mathrm{~min}$. Data were collected above the $\mathrm{CaCl}_{2}$ line. The data are represented as a threedimensional plot, viewed down the intensity axis, with energy ( $\mathrm{keV})$ along the $x$ axis and distance along the anode (mm) along the $y$ axis. The crosses represent the peak positions of the important phases as labelled. rutile wt $\%$ to that of the Magnéli phases can be seen to change as the anode moves through the diffraction lozenge. The results from above the $\mathrm{CaCl}_{2}$ are appreciably smoother than those from below. This is due to the considerably poorer data quality resulting from the absorption of the incident and diffracted beams by the electrolyte as shown in Fig. 15. The absorption components of the intensity corrections reflect this and the functions calculated for the data collected above (Fig. 11) and below (Fig. 12) the $\mathrm{CaCl}_{2}$ are shown in Fig. 16 . Fig. 17 shows the results of QPA from a cell cycled for $4 \mathrm{~h}$. The increase in the amount of rutile compared with the cells cycled for $10 \mathrm{~min}$ is clearly apparent. Analyses of rutile from all samples considered are shown in Fig. 18. The relationship between the measured amount of rutile on the anode and the cycling time is evident. These results can be used to calculate an approximate thickness of the rutile layer forming on each of the anodes. Note that as no verification of the quantitative phase analysis has been possible, these results must only be regarded as semi-quantitative and as such no estimate of error has been included.
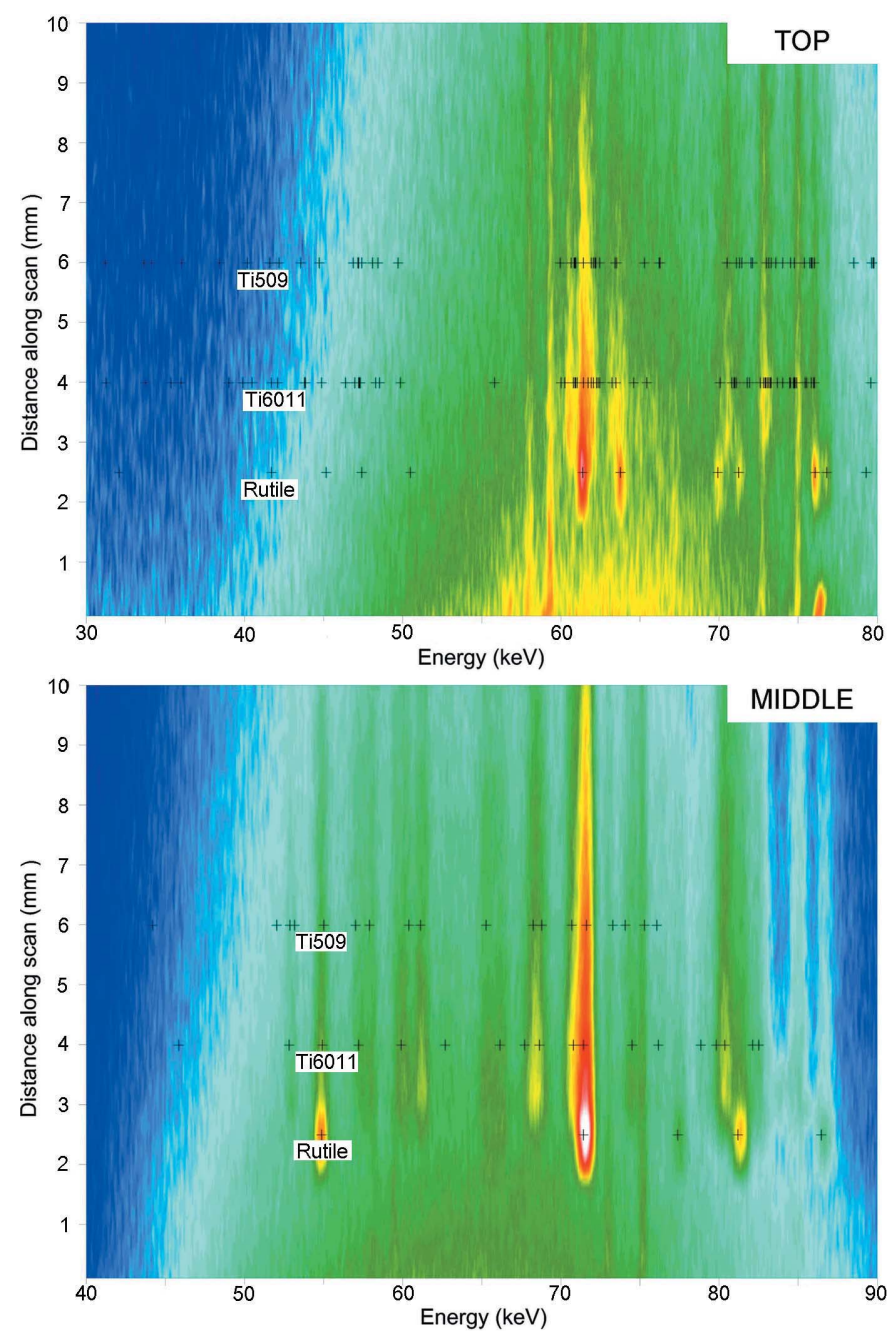

Figure 12

Accumulated EDD patterns from a cell cycled for $10 \mathrm{~min}$. Data were collected below the $\mathrm{CaCl}_{2}$ line. The data are represented as in Fig. 11. 
3.2.1. Calculation of rutile layer thickness. An estimate of rutile layer thickness may be calculated from the QPA of the anodes' diffraction patterns. The mean phase abundance of rutile was determined by averaging 40-70 values near the centre of the plot. This mean value was converted to a volume according to equation (15),

$$
\mathrm{Vol}_{\text {rutile }}=\mathrm{wt}_{\text {rutile }} /\left(\rho_{\text {rutile }} \times \mathrm{PR}\right)
$$
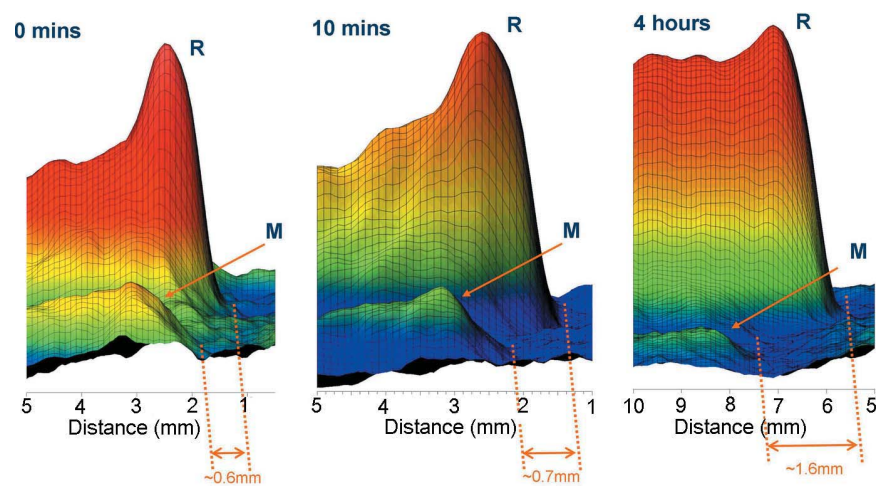

Figure 13

Accumulated EDD patterns from cells cycled for 0 and $10 \mathrm{~min}$ and $4 \mathrm{~h}$ viewed along the energy axis. The distance between the start of the rutile (R) and the Magnéli (M) phase peaks at each end of the scan represents the thickness of the rutile layer.

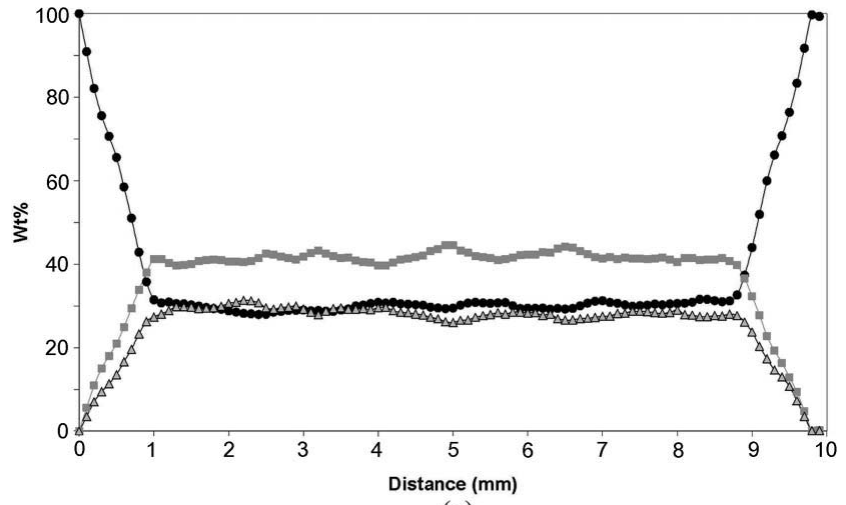

(a)

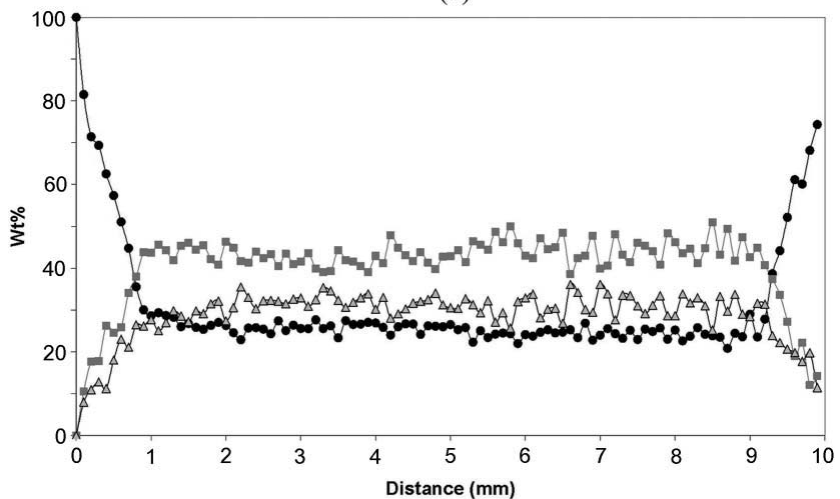

(b)

Figure 14

Results of quantitative phase analysis from a cell that had been cycled for 10 min. Black circles $=$ rutile, grey squares $=\mathrm{Ti}_{5} \mathrm{O}_{9}$, grey triangles $=$ $\mathrm{Ti}_{6} \mathrm{O}_{11}$. Data collected (a) from above the level of the $\mathrm{CaCl}_{2}$ electrolyte and $(b)$ from below the level of the $\mathrm{CaCl}_{2}$ electrolyte. where $\rho$ is assumed to be the crystallographic density of the phase, PR is the packing ratio of the phase and wt is the quantitative phase analysis of the phase. Note that using wt in this way assumes a starting value of $100 \mathrm{~g}$ of sample from which volumes of the individual components may be calculated and later converted to volume fractions by dividing by the sum of the calculated volumes. The error in wt is taken to be two standard deviations from the average value $(95 \%$ confidence limit) and thus is only an error in the precision of the measurement.

The phase volume can then be expressed as a volume percentage of the whole via equation (16), where $\mathrm{Vol}_{\text {total }}$ is the sum of the calculated volumes of all phases present in the sample:

$$
\mathrm{Vol} \%_{\text {rutile }}=100 \mathrm{Vol}_{\text {rutile }} / \mathrm{Vol}_{\text {total }} \text {. }
$$

The rutile layer thickness can then be calculated according to equation (17),

$$
\text { Thickness }_{\text {rutile }}=0.01 \times 0.5 \times \mathrm{Vol}_{\text {rutile }} \times \text { Thickness }_{\text {anode }},
$$

where 0.5 in equation (17) accounts for the contribution from both sides of the anode (i.e. two layers of scale in the beam).

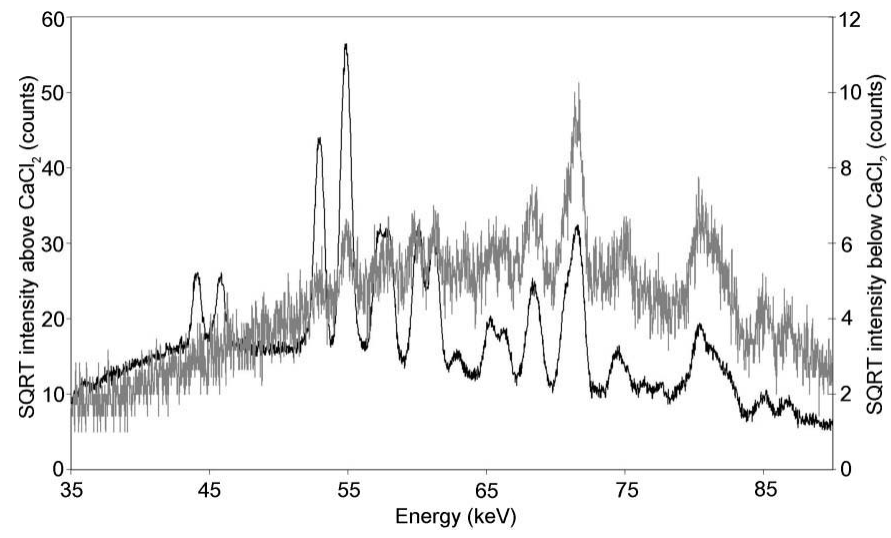

Figure 15

Diffraction patterns taken above (black) and below (grey) the surface of the $\mathrm{CaCl}_{2}$ electrolyte. Cell cycled for $10 \mathrm{~min}$.

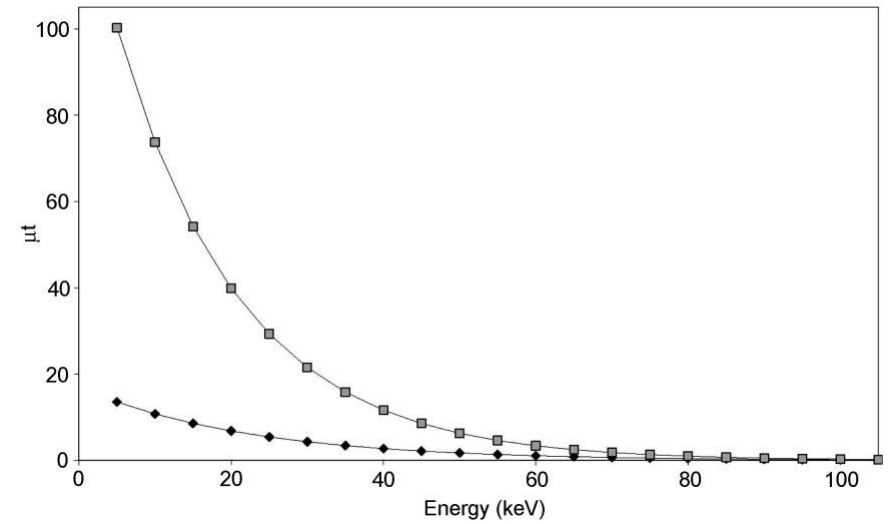

Figure 16

Absorption component of the intensity correction for a cell that had been cycled for 10 min calculated for diffraction data collected above (black diamonds) and below (grey squares) the $\mathrm{CaCl}_{2}$ electrolyte. 
Table 3

Rutile layer thickness estimated visually from accumulated diffraction patterns and calculated from results and quantitative phase analysis.

\begin{tabular}{rlll}
\hline & & \multicolumn{2}{l}{ Calculated thickness $(\mathrm{mm})$} \\
\cline { 3 - 4 } $\begin{array}{l}\text { Cycling } \\
\text { time (min) }\end{array}$ & $\begin{array}{l}\text { 'Measured' } \\
\text { thickness (mm) }\end{array}$ & $\mathrm{PR}_{\text {rutile }}=1$ & $\mathrm{PR}_{\text {rutile }}=0.3$ \\
\hline 0 & 0.6 & $0.3(2)$ & $0.7(2)$ \\
10 & 0.7 & $0.4(1)$ & $0.8(1)$ \\
60 & 0.7 & $0.5(2)$ & $0.9(2)$ \\
120 & 1.4 & $0.8(6)$ & $1.2(6)$ \\
240 & 1.6 & $0.9(5)$ & $1.3(5)$ \\
\hline
\end{tabular}

The thickness of the anode was determined by taking a number of measurements using a micrometer and using the average value. The error was once again taken to be two standard deviations of the average anode thickness.

Fig. 19 shows the results of these calculations assuming different packing ratios of rutile (grey squares, packing ratio $=$ 1 ; black diamonds, packing ratio $=0.6$ ). Error bars based upon the standard deviation of the calculated $\mathrm{wt} \%$ of rutile and the measured anode thicknesses have only been shown on one calculation for clarity. Note the layer thickness increases with

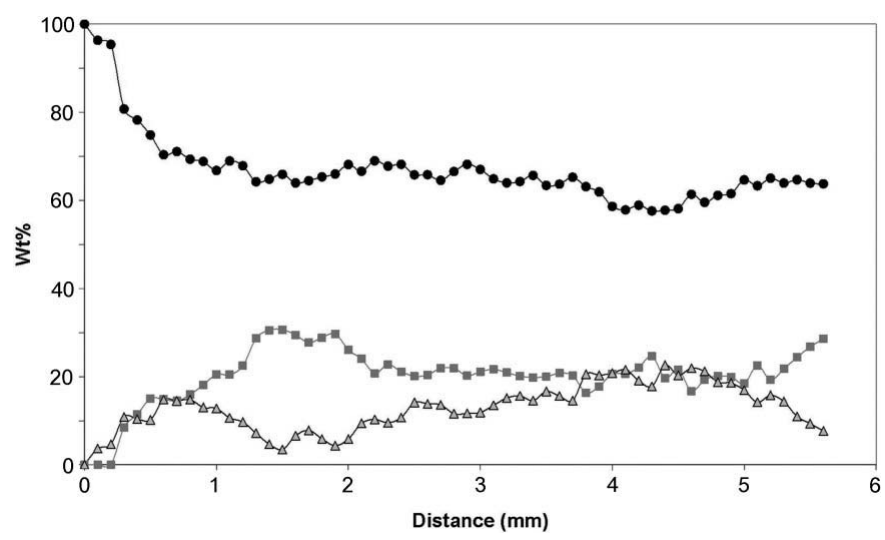

Figure 17

Results of quantitative phase analysis from a cell that had been cycled for $4 \mathrm{~h}$. Black circles $=$ rutile, grey squares $=\mathrm{Ti}_{5} \mathrm{O}_{9}$, grey triangles $=\mathrm{Ti}_{6} \mathrm{O}_{11}$. Data collected from below the level of the $\mathrm{CaCl}_{2}$ electrolyte.

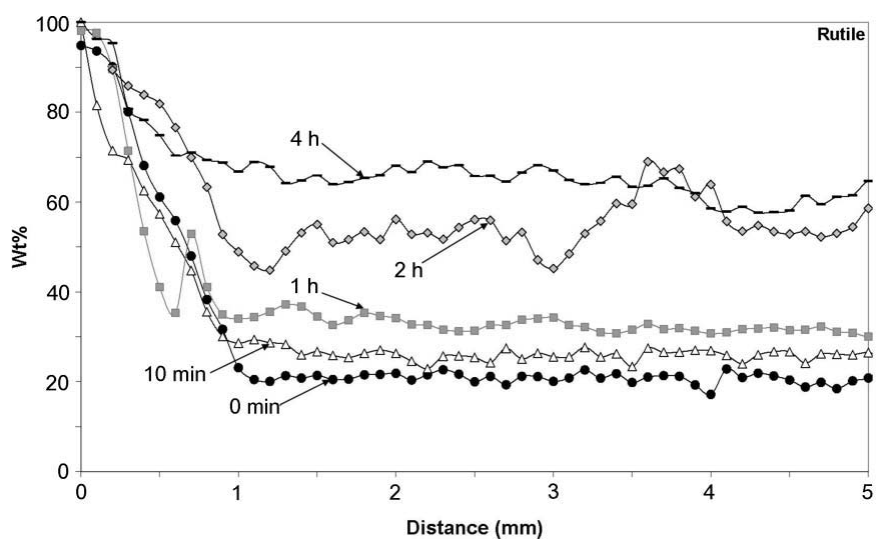

Figure 18

Comparison of rutile analyses over $5 \mathrm{~mm}$ of anode length for each of the electrolysis times considered in this study. the reduction of assumed packing density, as expected. Fig. 19 also shows (dark-grey circles) the values 'measured' from plots of the type in Fig. 11 (Table 3 gives the values). Both determinations show the thickness of the rutile layer to increase linearly with cycling time. However, the measured values are consistently higher than those calculated. This is due partially to the difficulty in estimating the starting position of the peaks used for the measurement but also to the likely low packing density of the rutile layer. The linearity of the relationship between layer thickness and cycling time and the order of magnitude of the layer thickness are consistent with indications from previous ex situ work (McGregor et al., 2006).

\section{Conclusions and future work}

A method has been developed for the quantitative phase analysis of energy-dispersive diffraction data using crystalstructure-based Rietveld refinement directly in energy space. This method has been developed and tested using standard materials and has then been applied to samples relating to the study of scale formation on inert anodes. Quantification has been achieved, but the issues relating to absorption by the electrolyte have limited the accuracy and worsened the lower limits of detection associated with this method. However, it has still been sufficiently effective to show a linear relationship between the thickness of the scales formed and the cycling times of the anodes examined. This is consistent with the findings of previous ex situ studies (McGregor et al., 2006).

It is proposed to repeat the examination of the cells considered in this study using neutron diffraction to compare the results and detection limits. When this has been done further post mortem laboratory studies will be conducted. This will entail mounting each cell in epoxy resin and sectioning for electron-probe microanalysis and laboratory micro-X-ray diffraction. In this way, determination of film thickness and identification of any additional minor phases may be achieved. This will be useful in the assessment of the accuracy of the energy-dispersive and neutron diffraction results.

The current work indicated the potential for further studies under normal operating conditions: namely in molten $\mathrm{CaCl}_{2}$ at

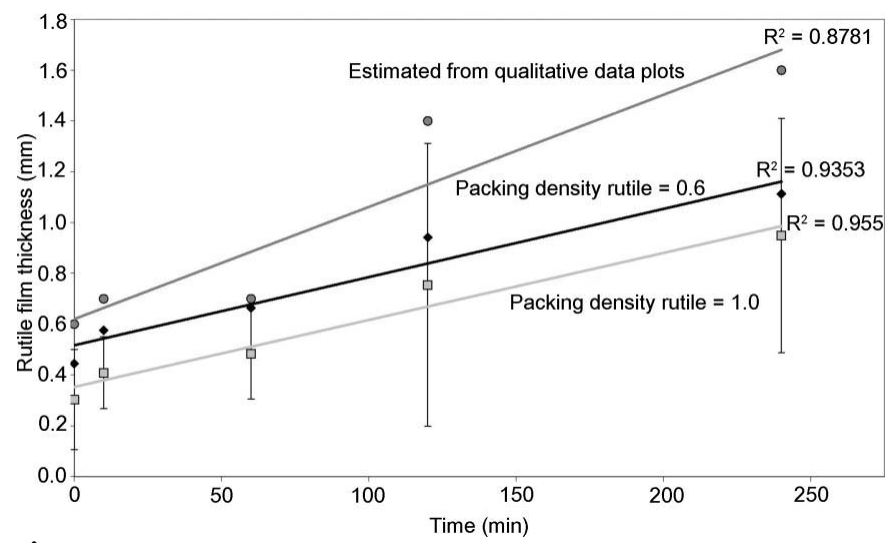

Figure 19

Rutile film thickness calculated from QPA (grey squares and black diamonds) and estimated from qualitative data plots (dark-grey circles) plotted against electrolysis time of the anodes. 
$1223 \mathrm{~K}$ with voltage applied to the electrodes. It may be necessary to redesign the electrolytic cell to reduce the path length of the beam in $\mathrm{CaCl}_{2}$ and to make the placement of the anode within the cell more accurate and reproducible to assist in its location in the X-ray beam. It may also be worth investigating other electrowinning systems which operate in less absorbing electrolytes via this technique.

The authors wish to acknowledge Daresbury SRS grant No. 46104 for beamtime, Station 16.4 beamline scientists Drs Dave Taylor and Tony Bell for assistance with data collection, and the Australian Major Research Facilities Program (AMRFP) for funding for travel, meals and accommodation under grant No. 06/07-S-05.

\section{References}

Andersson, S. \& Jahnberg, L. (1960). Ark. Kemi. 21, 413-426.

Ballirano, P. \& Caminiti, R. (2001). J. Appl. Cryst. 34, 757-762.

Barnes, P., Colston, S., Craster, B., Hall, C., Jupe, A., Jacques, S., Cockcroft, J., Morgan, S., Johnson, M., O'Connor, D. \& Bellotto, M. (2000). J. Synchrotron Rad. 7, 167-177.

Bordas, J., Glazer, A. M., Howard, C. J. \& Bourdillon, A. J. (1977). Philos. Mag. 35, 311-323.

Buras, B., Gerward, L., Glazer, A. M., Hidaka, M. \& Staun Olsen, J. (1979). J. Appl. Cryst. 12, 531-536.

Brown, A. S., Spackman, M. A. \& Hill, R. J. (1993). Acta Cryst. A49, 513-527.

Bruker (2003). TOPAS. Version 2.1. Bruker AXS Inc., Karlsruhe, Germany.

Frost, D. J. \& Fei, Y. (1999). Phys. Chem. Miner. 26, 415-418.

Glazer, A. M., Hidaka, M. \& Bordas, J. (1978). J. Appl. Cryst. 11, 165172.

Hall, C., Barnes, P., Cockcroft, J. K., Colston, S. L., Hausermann, D., Jacques, S. D. M., Jupe, A. C. \& Kunz, M. (1998). Nucl. Instrum. Methods Phys. Res. 140, 253-257.
Hall, C., Colston, S. L., Jupe, A. C., Jacques, S. D. M., Livingston, R., Ramadan, E. S. \& Barnes, P. (2000). Cem. Concr. Res. 30, 491-495. Hill, R. J. \& Howard, C. J. (1987). J. Appl. Cryst. 20, 467-474.

Larson, A. C. \& Von Dreele, R. B. (1985). GSAS. Report LAUR 86748. Los Alamos National Laboratory, New Mexico, USA.

Le Bail, A., Duroy, H. \& Fourquet, J. L. (1988). Mater. Res. Bull. 23, 447-452.

Madsen, I. C., Scarlett, N. V. Y., Cranswick, L. M. D. \& Lwin, T. (2001). J. Appl. Cryst. 34, 409-426.

Marezio, M. \& Dernier, P. D. (1971). J. Solid State Chem. 3, 340-348.

McGregor, K., Frazer, E. J., Urban, A. J., Pownceby, M. I. \& Deutscher, R. L. (2006). ECS Trans. 2, 369-380.

McGregor, K., Urban, A. J. \& Frazer, E. J. (2007) Application of a 'See-through' Electrolytic Cell for Titanium Electrowinning, Proceedings of the 11th World Conference on Titanium (Ti-2007), edited by M. Niinomi, S. Akiyama, M. Hagiwara, M. Ikeda \& K. Maruyama, pp. 127-130. Sendai: The Japan Institute of Metals.

Panero, S., Reale, P., Ronci, F., Rossi Albertini, V. \& Scrosati, B. (2000). Ionics, 6, 461-465.

Panero, S., Reale, P., Ronci, F., Scrosati, B., Rossi Albertini, V. \& Perfetti, P. (2001). Phys. Chem. Chem. Phys. 3, 845-847.

Restori, R., Schwarzenbach, D. \& Schneider, J. R. (1987). Acta Cryst. B43, 251-257.

Rietveld, H. M. (1969). J. Appl. Cryst. 2, 65-71.

Ronci, F., Scrosati, B., Rossi Albertini, V. \& Perfetti, P. (2000). Electrochem. Solid-State Lett. 3, 174-177.

Ronci, F., Scrosati, B., Rossi Albertini, V. \& Perfetti, P. (2001). J. Phys. Chem. B, 105, 754-759.

Rossi Albertini, V., Perfetti, P., Ronci, F. \& Scrosati, B. (2001). Chem. Mater. 13, 450-455.

Stinton, G. W. \& Evans, J. S. O. (2007). J. Appl. Cryst. 40, 87-95.

Weiss, A., Witte, H. \& Woelfel, E. (1957). Z. Phys. Chem. (Frankfurt Am Main), 10, 98-132.

Xu, Y.-N. \& Ching, W. Y. (1993). Phys. Rev. 48, 4335-4351.

Young, R. A. (1993). The Rietveld Method. Oxford University Press. Zhao, Y., Lawson, A. C., Zhang, J., Bennett, B. I. \& Von Dreele, R. B. (2000). Phys. Rev. B, 62, 8766-8776.

Zhao, Y., Von Dreele, R. B., Shankland, T. J., Weidner, D. J., Zhang, J., Wang, Y. \& Gasparik, T. (1997). Geophys. Res. Lett. 24, 5-8. 